\title{
Pengaruh Terpaan Tayangan Iklan Shopee Versi BlackPink terhadap Brand Loyalty Mahasiswa Jakarta
}

\author{
Susilawati, Lusia Savitri Setyo Utami \\ Susilawati.915160143@stu.untar.ac.id,Lusias@fikom.untar.ac.id
}

Fakultas Ilmu Komunikasi Universitas Tarumanagara.

\begin{abstract}
Shopee, as an e-commerce company, collaborated with BlackPink in 2018. The collaboration began with the sale of merchandise, followed by using Blackpink for Shopee advertising. The ad received wide attention from the public after an audience responded negatively. Therefore, this study discusses the Shopee ad version of the BlackPink. Shopee uses television to show BlackPink as a brand ambassador through advertisements. The purpose of this study was to determine whether there was an effect of the Blackpink version of Shopee Ad Impressions on Brand Loyalty, especially consumers in Jakarta. The theoretical basis used is the Display of Advertising Impressions and Brand Loyalty. This research uses an explanatory quantitative approach using survey methods. The population in this study were students in Jakarta with the sample used was 83 respondents. The results showed that there was a significant effect in the Ad Impression Variable on Brand Loyalty variables among Jakarta Students. The dimension in the Ad Impressions $(X)$ variable that most strongly influences the Brand Loyalty $(Y)$ variable is the content of the impression.
\end{abstract}

Keywords: Television, Advertising Exposure, Brand Loyalty, e-commerce

\begin{abstract}
Abstrak
Shopee sebagai perusahaan e-commerce melakukan kerja sama dengan BlackPink pada tahun 2018. Kerja sama diawali dengan adanya penjualan merchandise yang dilanjutkan dengan menggunakan BlackPink untuk iklan Shopee. Iklan tersebut mendapatkan perhatian masyarakat luas setelah ada khalayak yang menanggapi secara negatif. Oleh karena itu, penelitian ini membahas tentang iklan Shopee versi BlackPink tersebut. Shopee menggunakan media televisi untuk memperlihatkan BlackPink sebagai brand ambassador melalui iklan. Tujuan penelitian ini adalah untuk mengetahui ada tidaknya pengaruh Terpaan Tayangan Iklan Shopee versi Blackpink terhadap Brand Loyalty konsumen terutama terhadap Mahasiswa di Jakarta. Adapun landasan teoritik yang digunakan adalah Terpaan Tayangan Iklan dan Brand Loyalty. Penelitian ini menggunakan pendekatan kuantitatif bersifat eksplanasi menggunakan metode survei. Populasi dalam penelitian ini adalah mahasiswa di Jakarta dengan sampel yang digunakan adalah 83 responden. Hasil penelitian menunjukkan bahwa terdapat pengaruh yang signifikan dalam Variabel Terpaan Tayangan Iklan terhadap variabel Brand Loyalty di kalangan Mahasiswa Jakarta. Dimensi dalam variabel Terpaan Tayangan Iklan (X) yang paling kuat mempengaruhi variabel Brand Loyalty (Y) adalah Isi tayangan.
\end{abstract}

Kata Kunci: Televisi, Terpaan Iklan, brand Loyalty, e-commerce

\section{Pendahuluan}

Saat ini kemajuan e-commerce didukung oleh tumbuhnya teknologi internet. Dengan adanya teknologi internet dapat mempermudah masyarakat dalam kegiatan sehari-hari. Sebuah perusahaan e-commerce dengan nama yang terkenal merupakan suatu aspek yang penting bagi perusahaan.E- Commerce mulai memperkenalkan 
toko online yang mudah digunakan oleh masayarakat pada zaman era digital. Maka sebuah perusahaan harus memiliki strategi perluasan yang dilakukan dengan cara memperkenalkan berbagai macam atribut tambahan atau variasi promosi tayangan iklan. Perusahaan e-commerce yang melakukan promosi tersebut salah satunya Shopee.

Pada tahun 2015, Shopee pertama kali diluncurkan di Singapura sebagai pasar marketplace dan mall online sosial pertama dengan menggunakan internet. Pemilihan BlackPink sebagai pengisi acara ulang tahun Shopee yang bertema "Birthday sale 12.12" menjadi salah satu cara Chris Feng selaku Chief Executive Officer Shopee dan Reski Yanuar selaku Country Brand Manager Shopee dapat memutuskan dan merekrut BlackPink sebagai ambassador Shopee, melalui lagu BlackPink yang berjudul "Ddu Du Ddu Du" menjadi jingle iklan Shopee di televisi.

Terpaan tayangan iklan Shopee versi BlackPink di televisi menjadi pembahasan publik. Menurut salah satu audiens yang melihat iklan tersebut, pakaian yang digunakan oleh BlackPink memberikan dampak kurang baik bagi masyarakat. Sehingga menimbulkan terpaan tayangan iklan Shopee versi BlackPink di pertelevisian Indonesia. Menurutnya hal tersebut dapat bepengaruh dengan pola hidup yang berubah secara induvidu dan perubahan tersebut dapat memberikan dampak positif ataupun yang negatif (Anggriawan,2018). Pada latar belakang yang telah diuraikan diatas, penulis berusaha untuk mengetahui apakah terdapat pengaruh dari terpaan tayangan iklan terhadap brand loyalty melalui televisi untuk meningkatkan penjualan Shopee. Maka penulis mengajukan penelitian berjudul "Pengaruh Terpaan Tayangan Iklan Shopee Versi BlackPink Terhadap Brand Loyalty Mahasiswa di Jakarta"

Berdasarkan latar belakang di atas, penulis menentukan tujuan penelitian ini yaitu untuk mengetahui apakah ada Pengaruh Terpaan Tayangan Iklan Shopee Versi BlackPink Terhadap Brand Loyalty Mahasiswa di Jakarta.

Landasan teoritik yang dimasukkan dalam penelitian ini adalah konsep Terpaan Media dan konsep Brand Loyalty. Terpaan media massa merupakan kekuatan dahsyat yang dapat mempengaruhi sikap dan perilaku manusia. Penelitian tentang terpaan tayangan media televisi memiliki sifat dasar yang berpengaruh terhadap terpaan media yaitu intensitas, isi tayangan, dan durasi tayangan (Wells, 2000). Intensitas penggunaan media mengacu pada frekuensi dan durasi penggunaan media. Isi tayangan adalah isi pesan atau informasi pada tayangan iklan yang disampaikan kepada khalayak disajikan dengan lengkap dan jelas. Durasi adalah bagaimana khalayak memperhatikan iklan walaupun hanya melihat sekilas atau melihat iklan secara lengkap (Wells, 2000).

Konsep Brand Loyalty dilakukan untuk variabel Y yaitu loyalitas konsumen yang merupakan keputusan konsumen untuk setia atau loyal terhadap satu merek dengan melihat karakteristirk loyalitas konsumen produk yang telah memuaskan kebutuhan dan keinginan mereka dalam jangka waktu yang panjang dibandingkan membeli produk dengan merek baru. Setiap konsumen memiliki karakteristik yang berbeda-beda.

\section{Metode Penelitian}

Metode kuantitatif dinamakan metode tradisional, karena metode ini sudah cukup lama digunakan, sehingga sudah menjadi tradisi sebagai metode untuk penelitian. Metode ini disebut metode kuantitatif karena data penelitian merupakan 
angka-angka dan analisis menggunakan statisitik (Sugiyono dalam Marta \& William, 2016). Metode penelitian kuantitatif yang digunakan oleh penulis adalah survei yang merupakan metode riset dengan menggunakan kuisioner sebagai instrumen pengumpulan data (Kriyantono, 2014). Pada penelitian ini, populasi yang dipilih oleh peneliti adalah mahasiswa pengguna Shopee di wilayah Jakarta. Menurut Sugiyono (2017) ukuran sampel yang bisa di masukan dalam penelitian adalah 30-500 sampel. Maka pada penelitian ini memasukan hasil yang valid sebanyak 83 responden yang mewakili populasi Jakarta. Karena 83 responden tersebut masuk dalam ukuran teori tersebut. Peneliti menyebarkan kuisioner melalui google form.

\section{Hasil Penemuan dan Diskusi}

Dalam pengujian hipotesis peneliti menggunakan uji t, uji t dilakukan untuk menguji hipotesis yang menyatakan ada atau tidak adanya pengaruh dua variabel yang berpasangan. Pada variabel tersebut di bagi menjadi dua variabel yaitu "terpaan tayangan iklan" (Variabel X) dan "Brand Loyalty" (Variabel Y). Untuk menguji hasil penelitian menggunakan langkah-langkah uji t hipotesis hasil dari penelitian ini yang berpengaruh pada hasil uji:

Ha : Sig \&lt; a, Terpaan Tayangan Iklan dari seorang komunikator berpengaruh terhadap Brand Loyalty. Berdasarkan hasil Uji t, hipotesis ini dapat diterima.

Dapat disimpulkan variabel Terpaan Tayangan Iklan memberikan dampak kepada konsumen, semakin tingginya iklan terkena terpaan semakin tinggi pula tingkat Brand Loyalty konsumen pada perusahaan Shopee. Maka, hasil dari variabel $\mathrm{X}$ Terpaan Tayangan Iklan terhadap variabel Y Brand Loyalty mendapatkan hasil yang signifikan, sehingga Variabel $\mathrm{X}$ berpengaruh pada variabel $\mathrm{Y}$.

\section{Uji Validitas}

Tabel 1. Uji Validitas

\begin{tabular}{cccc}
\hline \multicolumn{1}{c}{ No Soal } & $\begin{array}{c}\text { Score Corrected Item } \\
\text { Total }\end{array}$ & Keterangan \\
\hline \multirow{1}{*}{$\mathbf{X}$} & 0,683 & Valid \\
\hline Likert & 0,475 & Valid \\
\hline Likert & 0,533 & Valid \\
\hline Likert & 0,628 & Valid \\
\hline Likert & 0,683 & Valid \\
\cline { 2 - 4 } & Likert & 0,475 & Valid \\
\cline { 2 - 4 } & Likert & 0,533 & Valid \\
\cline { 2 - 4 } & Likert & 0,628 & Valid \\
\cline { 2 - 4 } & Likert & 0,595 & Valid \\
\cline { 2 - 4 } & Likert & 0,646 & Valid \\
\cline { 2 - 4 } & Likert & 0,585 & Valid \\
\cline { 2 - 4 } & Likert & 0,557 & Valid \\
\hline & Likert & 0,488 & Valid \\
\hline Likert & 0,743 & Valid \\
\hline
\end{tabular}




\begin{tabular}{cccc}
\hline \multirow{4}{*}{$\mathbf{Y}$} & Likert & 0,608 & Valid \\
\cline { 2 - 4 } & Likert & 0,565 & Valid \\
\cline { 2 - 4 } & Likert & 0,452 & Valid \\
\cline { 2 - 4 } & Likert & 0,436 & Valid \\
\hline \multirow{3}{*}{ Likert } & 0,349 & Valid \\
\hline Likert & 0,728 & Valid \\
\hline Likert & 0,724 & Valid \\
\hline Likert & 0,427 & Valid \\
\hline Likert & 0,701 & Valid \\
\hline & Likert & 0,530 & Valid \\
\hline Likert & 0,719 & Valid \\
\hline
\end{tabular}

Sumber: SPSS Ver. 23

Dari hasil uji penghitungan validitas di atas dengan menggunakan SPSS ver. 23 peneliti menggunakan 83 responden yang mengetahui dan melihat iklan Shopee versi BlackPink Pengujian dilakukan dengan menjadikan 0,200 sebagai patokan terhadap kolom Corrected Item-Total Correlation. Jika angka berada dibawah 0,2 maka data dinyatakan tidak valid (gugur) dan jika angka berada diatas 0,2 maka data dinyatakan valid. Berdasarkan hasil perhitungan di atas, dari data variabel $\mathrm{X}$ terdiri dari 12 butir pertanyaan dalam variabel X "terpaan tayangan iklan" dari total keseluruhan tersebut dinyatakan valid atau di atas 0,200. Pada variabel Y "brand loyalty" terdiri dari 14 butir pertanyaan dalam variabel $\mathrm{Y}$ dinyatakan valid atau nilai angka diatas 0,200. Maka, dapat disimpulkan bahwa sebanyak 26 butir pertanyaan dalam variabel (X)“Terpaan Tayangan Iklan” memiliki nilai $r$ hitung \&gt; 0,200,yang berarti semua pernyataan pada X dan Y telah valid.

\section{Uji Reabilitas}

Tabel 2. Hasil Analisis Reliabitas X

\begin{tabular}{cc}
\hline $\begin{array}{c}\text { Cronbach's } \\
\text { Alpha }\end{array}$ & N of Items \\
\hline 0,889 & 12 \\
\hline
\end{tabular}

Uji reliabilitas adalah pengujian untuk mengetahui sejauh mana hasil pengukuran tetap konsisten apabila dilakukan dengan pengukuran dua kali atau lebih (Siregar, 2013). Terdapat syarata minimum untuk dinyatakan reliable yaitu apabila hasil korelasinya 0,6 atau lebih maka hasilnya dinyatakan reliable. Tetapi apabila nilai korelasinya di bawah 0,6 maka item tersebut dinyatakan tidak reliabel. Berdasarkan hasil analisis reliabilitas diatas, dapat disimpulkan bahwa variabel $\mathrm{X}$ (Terpaan Tayangan Iklan) dengan menggunakan dua belas (12) indikator hasilnya dinyatakan reliabel karena memiliki nilai korelasi > 0,6 yaitu Crondbach's Alpha $0,889>0,6$. 
Susilawati, Lusia Savitri Setyo Utami: Pengaruh Terpaan Tayangan Iklan Shopee Versi BlackPink terhadap Brand Loyalty Mahasiswa Jakarta

\section{Kesimpulan}

Berdasarkan hasil pembahasan dan hasil penelitian, maka dapat ditarik kesimpulan yaitu terpaan tayangan iklan Shopee di televisi memiliki pengaruh terhadap loyalitas pelanggan untuk bertransaksi di Shopee secara online. Artinya semakin sering atau tinggi seseorang terkena terpaan dari pesan-pesan iklan Shopee di televisi maka semakin tinggi loyalitas seseorang untuk memiliki minat bertransaksi di Shopee. Dimensi dari variabel terpaan tayangan iklan yang paling kuat mempengaruhi variabel brand loyalty yaitu isi tayangan. Oleh karenanya rekomendasi penulis berdasarkan penelitian ini untuk para produsen iklan adalah dengan memperhatikan dimensi isi tayangan dalam pembuatan iklan, karena dengan adanya dimensi tersebut memberikan kejelasan adanya isi tentang latar, gambar, dan konten yang menarik dalam iklan. Sehubungan dengan dimensi lainnya yang lebih lemah yaitu intensitas dan durasi, menurut penulis disebabkan oleh pemilihan media televisi yang mulai ditinggalkan khalayaknya khususnya mahasiswa yang menjadi rensponden penelitian ini. Oleh karena itu rekomendasi penulis untuk Shopee agar memilih sarana media lainnya selain televisi untuk beriklan.

\section{Ucapan Terimakasih}

Penulisan skripsi ini tentunya tidak terlepas dari pihak-pihak yang senantiasa membantu dan memberi dukungan serta bimbingan dari berbagai pihak. Banyak sekali yang memberikan kontribusi dan semangat kepada penulis selama penyusunan skripsi ini. Oleh karena itu, pada kesempatan ini, penulis mengucapkan terima kasih kepada yang pertama kepada Tuhan yang Maha Esa atas semua berkat dan kemudahan jalan yang telah diberikan-Nya kepada penulis. Peneliti juga mengucapkan terimakasih kepada Ibu Dr. Riris Loisa, M.Si. selaku Dekan Fakultas Ilmu Komunikasi Universitas Tarumanagara, bapak Yugih Setyanto, S.Sos., M.Si Wakil Dekan, Ibu Sinta Paramita, S.I.P., Ma Kaprodi S1, yang terakhir kepada Ibu Wulan Purnama Sari, S.I.Kom., M.Si.

Penulis meminta maaf jika ada salah kata dalam pembuatan penelitian ini. Penulis mengakui ada banyak kekurangan dalam penulisan skripsi ini. Penulis menerima kritik dan saran dari pembaca untuk membantu penulis agar lebih baik untuk kedepannya. Akhir kata, penulis menaruh harapan agar karya ilmiah ini agar bermanfaat bagi rekan pembaca.

\section{Daftar Pustaka}

Farady,William. (2016). Studi Terpaan Media Pemasaran Melalui Poting Instagram Terhadap Ekuitas Merek Pelanggan Sumoboo! (Analisis Eksplanatif Pada Komunitas Food Blogger \#WTFoodies). Jurnal Komunikasi, Universitas Tarumanagara

Irwansyah, Ekawati., Ernugtyas. (2016). Efek Iklan Televisi Program Keluarga Berencana. Jurnal Komunikasi, Universitas Tarumanagara.

Kriyanto, Rachmat. (2014). Teknik Praktis Riset Komunikasi. Jakarta: Kencana.

Kusniadji, Suherman., Jacqueline. (2016). Pengaruh Komunikasi Pemasaran melalui Event dan Iklan Terhadap Citra Merek Shopee. Jurnal Komunikasi.

McQuail, Denis. (2011). Teori Komunikasi Massa Buku 2 (6th ed). Jakarta : Salemba Humanika 
Morissan. (2010). Periklanan komunikasi pemasaran terpadu. Jakarta: KENCANA Prenamedia Group.

Nazir, Mohammad. (2013). Metode Penelitian. Bogor: Ghalia Indonesia

Nisfiannoor, Muhammad. (2013). Pendekatan Statistik Modern: Aplikasi dengan Software SPSS dan E-Views. Jakarta: Penerbit Trisakti

Akdon \& Ridwan. (2005). Rumus dan Data dalam Aplikasi Statistik. Bandung: Alfabeta

Sugiyono. (2017). Metode Penelitian Kuantitatif, Kualitatif, dan R\&D. Bandung: Alfabeta.

Sujarweni, V. Wiratna. (2014). SPSS Untuk Penelitian. Yogyakarta : Pustaka Baru Press.

Supranto. J. \& Dr. H. (2007) Nandan Liimakrisna, Perilaku Konsumen danStrategi Pemasaran, Jakarta: Mitra Wacana Media.

Wells, William., Jhon Burnett, Sandra Moriarty. (2000). Advertising Pririncples And Practice, Five Edition. New Jersey: Prentice-Hall International.

https://lifestyle.sindonews.com/read/1356209/166/blackpink-resmi-menjadi-brandambassador-platform-belanja-online-1542720001

https://inet.detik.com/business/d-3054826/misi-shopee-di-e-commerce-ke-indonesialalu-kuasai-asia 